\title{
Precordial counting: Evaluation and comparison of iodine-131 labelled albumin and technetium-99m in detection of left-to-right shunts
}

\author{
A.R. L OR I M ER, D. M C C A L L, A N D G. B O Y D \\ From the University Department of Medical Cardiology and the Respiratory Investigation Unit, \\ Glasgow Royal Infirmary
}

\begin{abstract}
Methods of precordial counting of radio-active isotopes in the detection of left-to-right intracardiac shunts are presented. Both iodine-131 labelled albumin and technetium-99m were used but the latter is preferred, especially for children, since it has a short physical half-life and emits a single gamma ray. Investigations were done to establish normal values and those in patients who had either rheumatic or congenital heart disease. All left-to-right shunts were confirmed at cardiac catheterization. False negative results were rare but false positive results can occur in the presence of congestive cardiac failure. It is possible to detect left-to-right shunts with a pulmonary to systemic flow ratio as low as $1 \cdot 2: 1$ and an estimate of this ratio can be made from the precordial curve. The main value of the method is as a preliminary investigation in the detection of intracardiac shunts.
\end{abstract}

The diagnosis of a left-to-right intracardiac shunt may be made in some instances by clinical and radiological investigations, but cardiac catheterization is necessary for confirmation, localization, and quantification. Not infrequently, however, patients present with findings which are inconclusive but which raise the possibility of a small intracardiac communication. In such patients it is desirable to exclude the presence of a left-toright shunt without recourse to cardiac catheterization. The intravenous injection of radioactive isotopes followed by precordial counting appears to offer a relatively simple and safe procedure to achieve this purpose (Huff, Parrish, and Crockett, 1957 ; Cornell, Braunwald, and Morrow, 1961). This communication deals with the further evaluation of the technique, and, in particular, the use of radioactive technetium $\left({ }^{99 \mathrm{~m} T c)}\right.$ (Clarke, Deegan, McKendrick, Herbert, and Kulke, 1966).

\section{MATERIALS AND METHODS}

Precordial counting was done in four groups of subjects :

1. 34 patients (mean age $38 \cdot 2$, range $12-68$ years) who had no cardiac abnormality on clinical, radiological or electrocardiographic investigation;

2. 39 patients with rheumatic heart disease without evidence of congestive cardiac failure (mean age $38 \cdot 0$,

IObtained from Radiochemical Centre, Amersham, Bucks. range $25-56$ years). The lesions included both mitral and aortic valve disease; in none of these patients was there clinical evidence of a shunt. The diagnosis was confirmed by right and left heart catheterization in a number of instances;

3. 35 patients (mean age $43 \cdot 0$, range $20-60$ years) with frank congestive cardiac failure due to either rheumatic heart disease or chronic lung disease ;

4. 31 patients (mean age $22 \cdot 6$, range $8-41$ years) in whom a left-to-right shunt was confirmed at cardiac catheterization by oxygen analysis, ascorbate injection, cineangiocardiography or by passing the catheter through the defect. An atrial septal defect was present in 22, ventricular septal defect in four, patent ductus arteriosus in four, and anomalous pulmonary veins in one.

The external detector was a sodium iodide thallium activated crystal measuring 2.5 by $2.5 \mathrm{~cm}$. The lead collimator was $10 \mathrm{~cm}$. long and $2 \mathrm{~cm}$. thick and had an aperture of $2 \mathrm{~cm}$. The apparatus was initially designed for use with iodine-131; such heavy collimation is not necessary for technetium-99m. The photomultiplier output was coupled to a ratemeter (EKCO 600B) and thence to a potentiometric recorder (TOA) with a paper speed of $3 \mathrm{~mm}$./ second. The detector was positioned just touching the skin over the fourth left interspace at the left sternal edge or over the second right interspace in the mid-clavicular line. Two radio-isotopes ${ }^{1}$ were used. Radio-iodinated human serum albumin (RISA) was diluted as required with sterile saline to a dosage of $25-30 \mu \mathrm{c}$ in adults and $10-15 \mu \mathrm{c}$ in children. The technetium-99m was obtained by saline elution from a generator column 
of molybdenum-99 on an alumina support and was sterilized before use. A dosage of $0 \cdot 6-0.8 \mathrm{mc}$. contained in a calibrated injection chamber of 1.4 or 2.4 ml. (Becton Dickinson Cat. No. 02-0027) was injected by a flushing dose of saline through an 18 gauge Teflon cannula inserted into a median antecubital vein. Patients rested in the supine position for 15 minutes before the investigation.

The data have been analysed in two ways. The first was reported by Carter, Bajec, Yannicelli, and Wood (1960) for use in dye dilution studies and by Folse and Braunwald (1962) in radio-isotope investigations. The time taken to reach maximum activity after appearance of the isotope in the counting field was noted. A similar time interval was measured from the point of maximum activity, and the height above the baseline at this point $(\mathrm{Ct})$ was compared with the maximum deflection $(\mathrm{Cmax})$ as the ratio $\mathrm{Ct} / \mathrm{Cmax}$. In patients with a normal circulation, peak activity was reached quickly and then fell off as the isotope was washed out of the counting field. Patients with a left-to-right shunt had a significantly higher ratio of $\mathrm{Ct} / \mathrm{Cmax}$ due to persistence of isotope in the counting field as it recirculated through the defect. In the second method, reported by Cornell et al. (1961), the descending limb of the curve was replotted on semilogarithmic paper and the rate of disappearance of the isotope was expressed as the percentage decline of isotope concentration per second. In addition, the time taken between the appearance of the isotope in the heart and maximum activity in the left ventricle was measured in seconds and expressed as the buildup time. The product of the build-up time and percentage decay per second was then calculated.

In the earlier part of the study, technetium-99m was not available and measurements were made using RISA alone. Subsequently, RISA and technetium$99 \mathrm{~m}$ were used consecutively with an interval of 10-15 minutes between injections. The patient remained in the same position throughout the entire investigation.

When using iodinated albumin the count rate was about 300 pulses per second. The EKCO ratemeter that we are using has a variable time constant relating to the mean probable error of the count rate. With albumin the mean probable error was $10 \%$, and this corresponds to a time constant of about $1 / 6$ second. When technetium was used the count rate was 800 1,000 pulses per second and the mean probable error was again $10 \%$, corresponding to a time constant of approximately $1 / 20$ second.

\section{RESULTS}

Representative curves from right lung counting in a normal subject, a patient in severe congestive cardiac failure, and a patient with an atrial septal defect are shown in Figures 1, 2, and 3. The ranges of build-up times, percentage decay, and products are shown in Table $I$. Because of the lower count rate, curves for RISA are less 'smooth' than those obtained with technetium. Our results were similar to those reported previously in the literature. In patients with a left-toright shunt, build-up times were similar to those
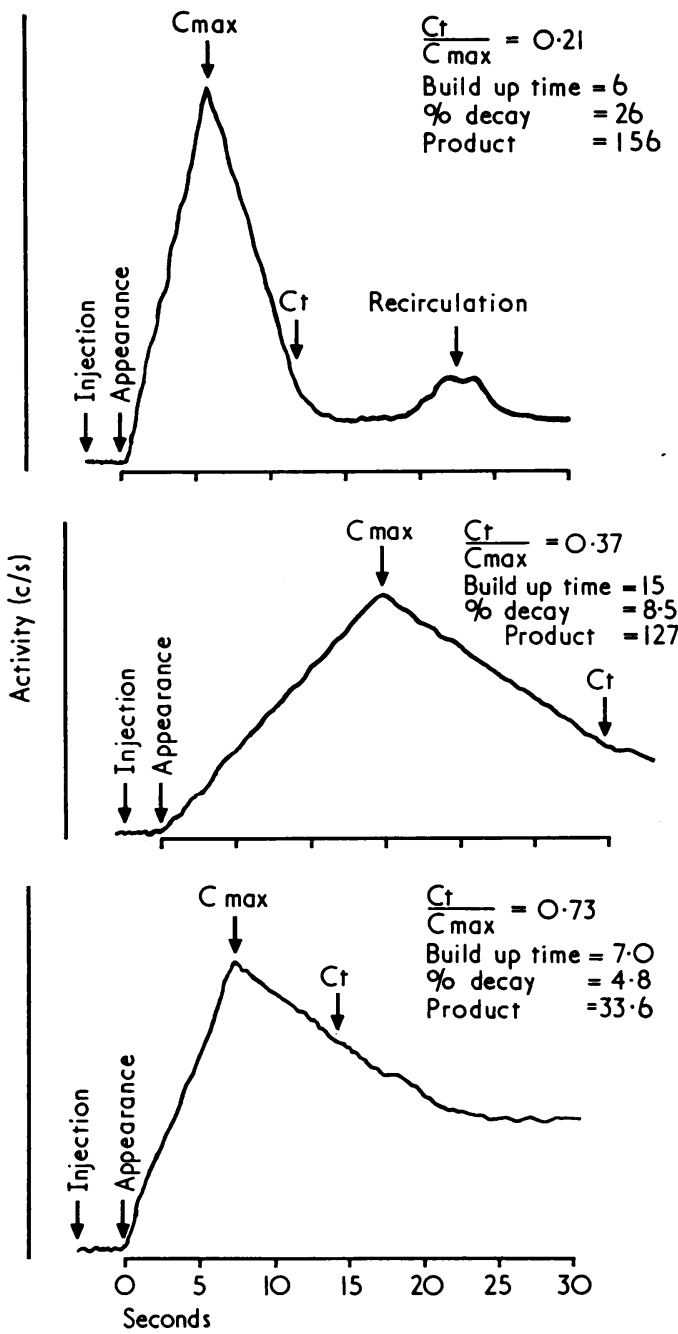

FIG. 1. (Top) Normal subject. Right lung curve using $99 m T c$.

FIG. 2. (Middle) Patient with severe congestive cardiac failure. Right lung curve using $99 m$ Tc.

FIG. 3. (Bottom) Patient with atrial septal defect. Right lung curve using $99 m$ Tc.

of normal subjects but the percentage decay per second was reduced, due to recirculation of isotope through the defect. This meant that the product of these measurements was smaller than that 
found in normal subjects, the mean being 41 compared with 113. A false negative result for a shunt was obtained in one patient in whom the product was 83 compared to the lowest normal product of 62. This patient had a small ventricular septal defect not demonstrated by oxygen analysis but diagnosed by cineangiocardiography.

Due to circulatory slowing, patients in cardiac failure had a markedly prolonged build-up time in association with a diminished percentage decay per second so that the mean product (96) fell between values found in normal subjects (113) and in those with a left-to-right shunt (41). Severe congestive failure can make it difficult to exclude the presence of a shunt, since four patients with a confirmed left-to-right shunt had a product value above 42 , which was the lowest product found in patients with severe failure due to rheumatic heart disease.

Patients with rheumatic heart disease but no clinical evidence of congestive failure also had a longer build-up time than normal subjects, the mean being $13 \cdot 4$ as compared to $10 \cdot 2$ seconds. The percentage decay per second was also slower than in normal subjects but more rapid than was found in cardiac failure or where a shunt was present. There was no difficulty in differentiating patients with rheumatic heart disease from those with a left-to-right shunt.

The results obtained from counting over the fourth left interspace at the sternal border are shown in Figures 4 and 5. A clear separation was found between patients with a left-to-right shunt and other subjects no matter whether the method of calculation used was that of the product of

\section{T A B L E I}

VALUES FOR BUILD-UP TIME, PERCENTAGE DECAY PER SECOND, AND THEIR PRODUCT IN PATIENTS WITH AND

\begin{tabular}{|c|c|c|c|c|c|c|}
\hline \multirow{2}{*}{ 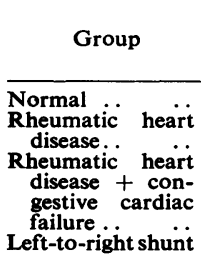 } & \multicolumn{2}{|c|}{$\begin{array}{l}\text { Build-up } \\
\text { Time (sec.) } \\
\text { Mean Range }\end{array}$} & \multicolumn{2}{|c|}{$\begin{array}{c}\% \text { Decay } \\
\text { per Sec. } \\
\text { Mean Range }\end{array}$} & \multicolumn{2}{|c|}{$\begin{array}{c}\text { Product } \\
\text { Mean Range }\end{array}$} \\
\hline & $\begin{array}{l}10 \cdot 2 \\
13 \cdot 4\end{array}$ & $\begin{array}{l}6-21 \\
9-19\end{array}$ & $\begin{array}{r}11.9 \\
9.5\end{array}$ & $\begin{array}{l}5 \cdot 3-20 \\
4 \cdot 8-15 \cdot 8\end{array}$ & $\begin{array}{l}113 \\
121\end{array}$ & $\begin{array}{l}62-185 \\
81-180\end{array}$ \\
\hline
\end{tabular}

percentage decay per second and the build-up time or the ratio of $\mathrm{Ct} / \mathrm{Cmax}$. The least satisfactory differentiation occurred when overt congestive cardiac failure was present.
The results from right lung counting are shown in Figure 6. As expected, similar values for $\mathrm{Ct} /$ Cmax were obtained after injection of RISA or technetium-99m. In addition, the differentiation between patients with and without a left-to-right shunt was comparable to that found by counting at the left sternal edge.

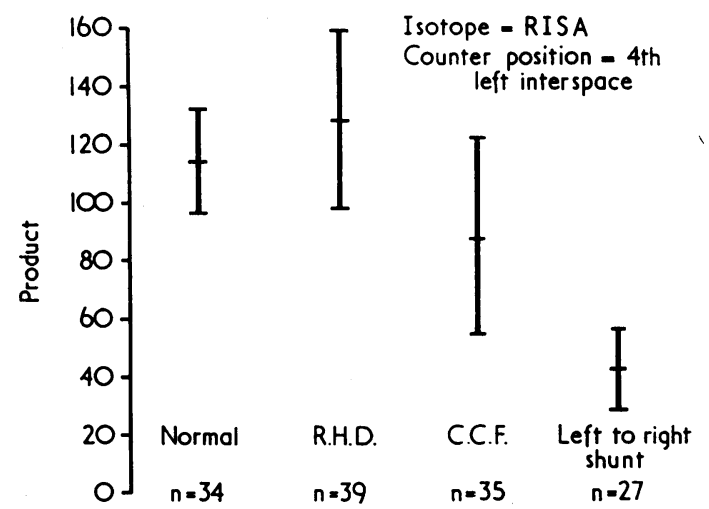

FIG. 4. Product of build-up time and percentage decay per second in patients with and without a left-to-right shunt. Mean \pm 1 S.D. are shown along with the number of subjects in each group.

Precordial counting appears reliable in the $\overline{\bar{o}}$ detection of significant left-to-right shunts. Pro- 3 cedures used in this department for shunt detection during cardiac catheterization include oxygen analysis (initially oxygen saturation, oxygen tension measurements are now also available), ascorbate injection, and cineangiocardiography. Table II compares the results obtained in 27 patients in whom all methods were used. Oxygen

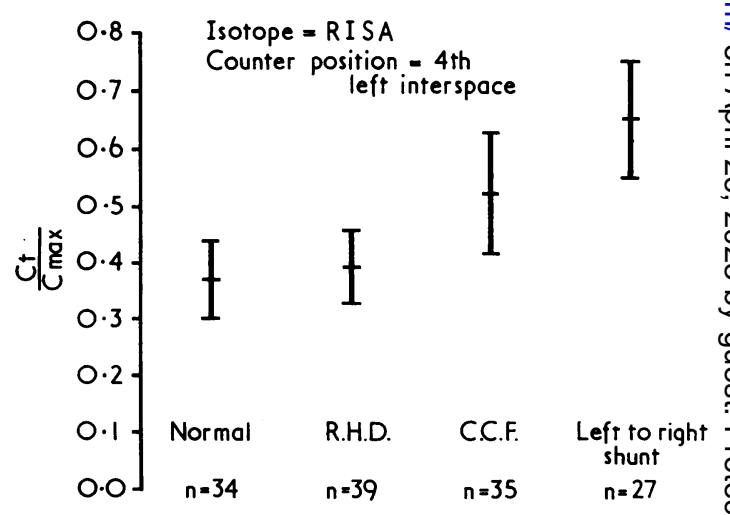

FIG. 5. Ratio of Ct/Cmax in patients with and without a left-to-right shunt. Mean \pm 1 S.D. are shown along with the number of subjects in each group. 
analysis was found unsatisfactory for shunt detection in patients with a small left-to-right shunt, and this investigation had to be combined with ascorbate injection to ensure diagnosis. Using precordial counting, values indicative of a left-to-right shunt have been found with a pulmonary to systemic flow ratio as low as $1 \cdot 2: 1$. There were no examples of a large left-to-right shunt not being detected by precordial counting. All patients with a pulmonary to systemic flow ratio of $2: 1$ or more had a confirmatory precordial count.

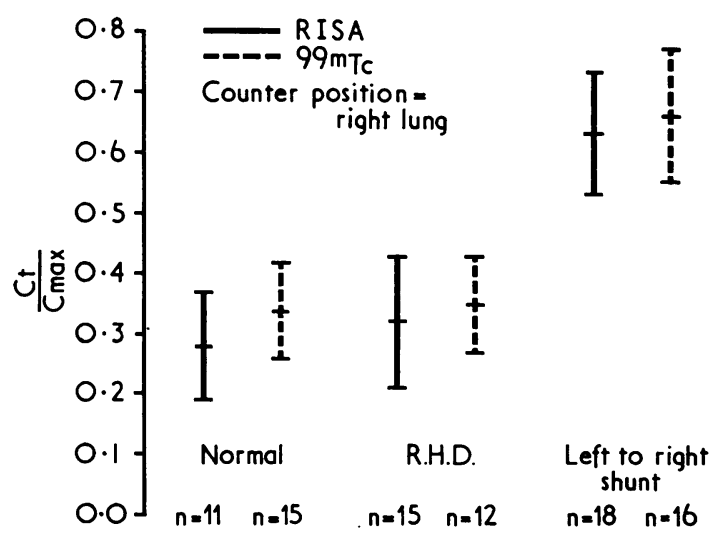

FIG. 6. Ratio of $\mathrm{Ct} / \mathrm{Cmax}$ in patients with and without a left-to-right shunt. Mean \pm 1 S.D. are shown along with the number of subjects in each group.

PULMONARY TO SYSTEMIC FLOW RATIO An estimate of pulmonary to systemic flow ratio can be calculated by standard methods from oxygen saturation data obtained at cardiac catheterization. The value can, of course, be only approximate due to streaming effects within the heart in the presence of a shunt, but the measurement does help in assessing the size of the lesion. Figure 7 shows the relationship between the pulmonary to systemic flow ratio calculated from oxygen saturation data plotted against the product of build-up time

T A B L E II

ACCURACY OF METHODS OF SHUNT DETECTION: COMPARISON OF OXYGEN ANALYSIS, ASCORBATE INJECTION, AND PRECORDIAL COUNTING

\begin{tabular}{c|c|c|c}
\hline \multirow{2}{*}{$\begin{array}{c}\text { No. of } \\
\text { Patients }\end{array}$} & \multicolumn{3}{|c}{ Shunt Detected by } \\
\cline { 2 - 3 } & Oxygen Analysis & $\begin{array}{c}\text { Ascorbate } \\
\text { Injection }\end{array}$ & Precordial Counting \\
\hline 12 & Yes & Yes & Yes \\
6 & No & No & No \\
7 & No or & Yes & Yes \\
No & No in 1 & Yes & Equivocal in 1 \\
\hline
\end{tabular}

and percentage decay. As indicated by Cornell et al. (1961), an estimate of the size of a shunt can be obtained from precordial counting by employing the appropriate regression equation. Similarly, a correlation coefficient of 0.74 was

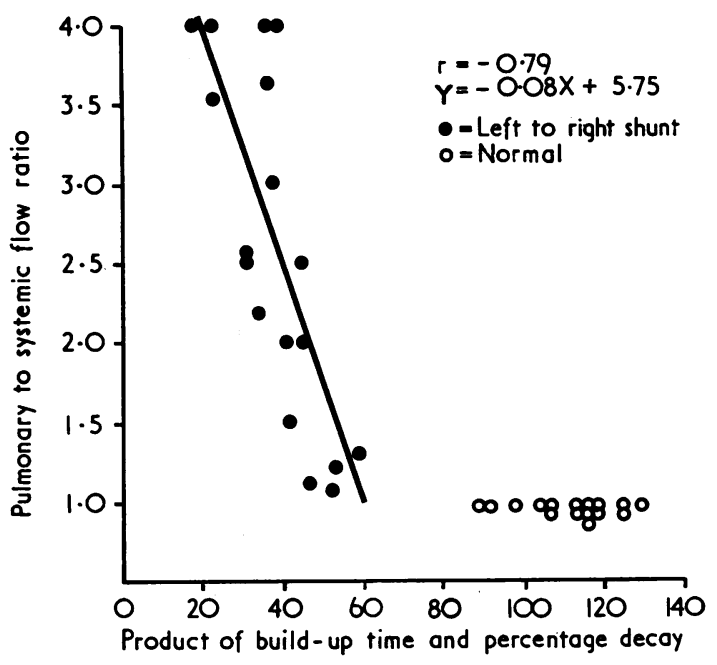

FIG. 7. Relationship between calculated pulmonary to systemic flow ratio and product of build-up time and percentage decay per second.

found when the ratio of $\mathrm{Ct} / \mathrm{Cmax}$ was plotted against the pulmonary to systemic flow ratio obtained from oxygen saturation data. The regression equation was $Y=10 \cdot 0 X-4 \cdot 7$, where $Y=$ pulmonary to systemic flow ratio and $\mathrm{X}=$ ratio of $\mathrm{Ct} / \mathrm{Cmax}$.

\section{DISCUSSION}

Precordial counting is a simple technique, requiring only standard radio-isotope counting equipment, although more complex recording equipment can, of course, be incorporated (Clarke et al., 1966). The short physical half-life of six hours of technetium-99m along with the virtual absence of $\beta$ radiation by the emission of a single gamma ray of $0.14 \mathrm{MeV}$ makes this isotope especially suitable for use in children. Excretion is rapid although stable iodine is stild administered to minimize thyroidal uptake of the isotope. Higher doses can safely be administered which produce higher counting rates and increase the accuracy of the method. The whole body radiation dose from $1 \mathrm{mc}$. of technetium-99m is in the order of $0.01 \mathrm{rad}$. which is much less than that 
received during a cardiac catheterization. This isotope does, however, require more elaborate preparation and monitoring of the eluted yield than does the use of RISA, which is still useful in centres only seldom using precordial counting or where cardiac output is being measured (Lorimer, Boyd, McCall, Mills, and Moran, 1969).

Recording with the crystal positioned over the fourth left interspace at the sternal edge has been suitable for detection of shunts at atrial or ventricular level. When the shunt, such as a patent duct, enters the pulmonary artery there is no abnormal circulation through the right side of the heart. When this lesion is suspected curves should be recorded over the second right and left interspaces. It is possible to demonstrate a relatively normal right lung curve and an abnormal left lung curve due to the main part of the increased flow being diverted through the left lung.

In common with other workers (Cornell et al., 1961 ; Clarke et al., 1966), we consider that external counting is of value in patients who are referred on account of a systolic murmur and where there is difficulty in excluding a shunt on clinical and radiological evidence. The results reported indicate that external counting can detect shunts with a pulmonary to systemic flow ratio as low as $1 \cdot 2: 1$. Smaller shunts are not likely to be detected but probably do not, in any case, require correction. When the patient is asymptomatic, and has a normal precordial curve and no other abnormal clinical features, we feel it justifiable to withhold cardiac catheterization. Conversely, any precordial curve that suggests a shunt should be followed by cardiac catheterization to localize and quantify the lesion.

\section{REFERENCES}

Carter, S. A., Bajec, D. F., Yannicelli, E., and Wood, E. H. (1960). Estimation of left-to-right shunt from arterial dilution curves. J. Lab. clin. Med., 55, 77.

Clarke, J. M., Deegan, T., McKendrick, C. S., Herbert, R. J. T., and Kulke, W. (1966). Technetium-99m in the diagnosis of left-toright shunts. Thorax, $21,79$.

Cornell, W. P., Braunwald, E., and Morrow, A. G. (1961). Precordial scanning. Applications in the detection of left-to-right circulatory shunts. Circulation, 23, 21.

Folse, R., and Braunwald, E. (1962). Pulmonary vascular dilution curves recorded by external detection in the diagnosis of left-toright shunts. Brit. Heart J., 24, 166.

Huff, R. L., Parrish, D., and Crockett, W. (1957). A study of circulatory dynamics by means of crystal radiation detectors on the anterior thoracic wall. Circulat. Res., 5, 395.

Lorimer, A. R., Boyd, G., McCall, D., Mills, R. J., and Moran, F. (1968). Clinical applications of praecordial counting. In Blood Flow through Organs and Tissues, ed. W. H. Bain and A. Murray Harper, pp. 79-88. Livingstone, Edinburgh. 